the end of the voyage all combine to make a sea trip pleasant or unpleasant. It is probable, too, that the rapid improvement in the class of cases I have named is due to the following causes: (1) enforced rest and change of scene; (2) the constant respiration of pure air free from inert impurities and which is only to be found in sea air ; (3) open-air treatment; (4) greater equability of temperature and the soothing effect of "ozone" on the constitution ; (5) certain specific substances in sea air ; (6) changes of climate through the different "regions" of the ocean. These above conditions are what we realise in our mind when we contemplate sending to sea a patient of the class likely to derive benefit.

Nervous complaints are so numerous and varied in their manifestations that they can only be spoken of generally. It may, however, be stated broadly that for all those anomalous affections of the nervous system that are not accompanied by any actual disease of the brain or spinal cord, but which are often dependent either upon mental causes or derangement of the digestive organs, we have in a sea-voyage a most valuable and successful mode of treatment. In fact, there are no cases in which, as a rule, the effects of sea-life are more strikingly beneficial than in these. The change of scene, the different mode of life, and the varied social conditions, usually exercise the most cheering influence, not only upon the bodily health but also (which is equally important in complaints of this class) upon the mental state; so that the nervous patient, after a month or two at sea, is often altogether a different being from what he was when he sailed.

But with regard to the more serious diseases of the nervous system, such as paralysis, epilepsy, melancholia, and mania, it is necessary to speak much more guardedly; and it is only after all the circumstances of such a case have been carefully weighed by the medical man in attendance that it will be possible to form a decided opinion as to the advisability of a sea voyage. This extract from a sailor's log speaks for itself. Having circumnavigated the ocean on more than one occasion I speak with some authority. It is well to know the "ropes" and to be experienced before one gives an opinion. Nevertheless, it is a good excuse to send a person of unsound mind to sea when you want to get rid of him. But the most honourable action, as a rule, is to advise the detention of a person of unsound mind in a residential home where he will have a better chance of recovery.-I am, Sirs, yours faitbfully,

Alton, Hants, Sept. 13th, 1902. J. F. BRISCOE

\section{A DISCLAIMER.}

\section{To the Editors of THE LANCET.}

Sins,-The British Medical Journal published last week a short note by me on the use of paraffin for restoring the bridge of the nose. Some of the daily papers have made "copy" of it, and have named me as though I had invented the method. I wish to say that I had nothing whatever to do with the matter and I wish it could have been prevented. - I am, Sirs, yours faithfully,

Sept. 15th.

STEPHEN PAGET.

\section{A MEDICAL ASPECT OF THE EDUCATION BILL.}

To the Editors of THE LANCET.

SIRS,-In order that education should be efficient it is surely necessary that the children should be in the best possible condition for receiving it. It has long been known that the eyes of our board school children are defective and the recent discussion at the Otological Society clearly showed that the ears and throats urgently require attention. Apart from the special senses I would ask, Does not the general condition of the children, especially as regards communicable diseases such as those of the skin and tuberculosis, require supervision? If a child is compelled by law to attend school the parents have a right to demand that the child runs no risk by so doing. The subject has been thoroughly recognised in some countries-Germany and Switzerland, for example-where every child is medically examined on entering the schools and all defects are, as far as is possible, rectified. Such examination and treatment must be of the greatest value from the educational standpoint and must add to the physical and intellectual vigour of a nation. It seems clear that some system is necessary in this country.

I am, Sirs, yours faithfully,

Savile-row, W., Sept. 15th, 1902 ARThUR H. Cheatle

\section{THREADWORMS AND APPENDICITIS.}

\section{To the Editors of THE LANCET.}

Sirs, - In an annotation in THE LANCET of Sept. 6th, p. 687, the occasional discovery of threadworms in the appendix is discussed. It is there stated that Professor Bégouin could find only a single reference to the existence of threadworms in an excised appendix. It may therefore be worth noting that in a case of recurrent appendicitis occurring in a young woman I found at the operation that the appendix was crammed with threadworms, in a lively condition. The appendix itself was thickened but not ulcerated. Probably many similar cases have occurred without being recorded, but in a large number of such operations I have only met with threadworms in this one case. Few things, however, have really escaped the observation of our ancestors, and Santorini nearly 200 years ago (in 1724) in his careful description of the appendix noted that it was often the resort of intestinal worms and suggested that its function might be to form a safe retreat for them to breed in. This theory may not perhaps be generally accepted but no more ingenious one exists. It is of interest to note that the vermiform appendix was first described in 1524 by Carpi, that Columbus was interested in it, and that American surgeons have since been prominent in demonstrating its importance. By a curious coincidence appendicitis was definitely described for the first time in 1824, exactly 300 years after the anatomical recognition.

I am, Sirs, yours faithfully,

J. Hutchinson, Jun.

Cavendish-square, W., Sept. 15th, 1902.

\section{THE ELECTION OF A DIRECT REPRESEN- TATIVE TO THE GENERAL MEDICAL COUNCTL. \\ To the Editors of THE LANCET.}

Srns,-The fact that Mr. Joseph Smith has placed the medical profession of England and Wales to the great and totally unnecessary expense of a contested election for the office of Direct Representative raises a question which the personalities and professional positions of Mr. Joseph Smith and Mr. George Brown would otherwise have rendered quite superfluous and immaterial to the profession at large.

The apology advanced by these gentlemen for Mr. Smith's obtrusion on public notice is that he is supported in his action by the Medical Practitioners' Association. Is this assertion correct?-in other words, have the members of that association been consulted on the matter and authorised this statement on their behalf? I am led to question this because there seems reason to believe that the members of this association are not even informed of matters which really are of direct personal interest and of the first importance to themselves.

If the members of this association are kept in ignorance of important facts it becomes all the more essential for a definite statement to be made as to the manner in which they have been consulted and have given Mr. Joseph Smith their authority to represent their views at this particular juncture. I am, Sirs, yours faithfully,

Sept. 15th, 1902 F.R.C S.

\section{THE PROPORTION OF THE MARRIAGE- \\ TO THE BIRTH-RATE IN DIFFERENT CLASSES OF THE POPULATION IN ENGLAND. \\ To the Editors of THE LANCET.}

SIRS,-I quote an extract from the statistics of the County of London issued last week by the London County Council :-

There has been a decided improvement in recent years in the marriage rate for London. In 1894 it reached its lowest point-17 per
1000 . In 1899 it was $18^{\circ} 4$ per 1000 . The birth-rate does not show a 